\title{
CFD fire simulation using mixture fraction combustion and finite volume radiative heat transfer
}

In: Journal of Fire Protection Engineering 2003.

Vol. 13, No. 1, pp. 11-36.

Reprinted with permission from the publisher. 


\title{
CFD Fire Simulation Using Mixture Fraction Combustion and Finite Volume Radiative Heat Transfer
}

\author{
J. E. Floyd ${ }^{1, *}$, K. B. McGrattan ${ }^{2}$, S. HostikKa ${ }^{3}$ and H. R. Baum ${ }^{2}$ \\ ${ }^{1}$ Hughes Associates, Inc., 3610 Commerce Dr., \\ Suite 817, Baltimore, MD 21227-1652, USA \\ ${ }^{2}$ Building and Fire Research Laboratory, \\ National Institute of Standards and Technology, \\ 100 Bureau Drive Stop 8640, \\ Gaithersburg, MD 20899-8640, USA \\ ${ }^{3}$ VTT Building and Transport, Espoo, Finland
}

\begin{abstract}
A computational fluid dynamics (CFD) model of fire and smoke transport is described. Combustion is represented by means of a single conserved scalar known as the mixture fraction. Radiation transport is approximated in the gray gas limit. The algorithms have been incorporated in the Fire Dynamics Simulator (FDS), a computer program maintained by the National Institute of Standards and Technology. Sample calculations are presented demonstrating the performance of the new algorithms, especially as compared to earlier versions of the model.
\end{abstract}

KEY WORDS: mixture fraction, computational fluid dynamics, fire simulation, radiation heat transfer.

\section{INTRODUCTION}

$\mathbf{T}$ HE SIMULATION OF fires using computational fluid dynamics (CFD) is challenging due to the need to resolve length scales ranging from those characteristic of the combustion processes to those characteristic of the mass and energy transport throughout an entire building. The width of a diffusion flame is on the order of a millimeter; the eddies associated with the

*Author to whom correspondence should be addressed. E-mail: jfloyd@haifire.com

Journal of Fire Protection EngineEring, Vol. 13-February 2003 
entrainment of air into a fire are of the order of centimeters; and the flow fields generated by a fire span an entire building. While it is possible to create a combustion model that tracks the significant species required to calculate the heat release rate, it is too expensive to construct a grid fine enough to resolve individual flame sheets except in cases where the domain is very small. For example, consider a small compartment $1 \mathrm{~m}$ on a side. If the combustion length scale is assumed to be $1 \mathrm{~mm}$ and the hydrodynamic scale $1 \mathrm{~cm}$, this compartment would require one billion computational cells at the combustion length scale and one million cells at the hydrodynamic scale. Few computers exist that can do a calculation with a billion cells. Even if current desktop computers could handle the calculation, it would take 10,000 times as long to perform a billion node transient calculation as compared to a million node calculation. A method, therefore, is needed to model the combustion chemistry in a manner that can be used at the length scales of the resolvable flow field.

The Fire Dynamics Simulator (FDS) [1,2], developed at the National Institute of Standards and Technology (NIST), originally used Lagrangian particles to represent burning fuel gases, hereafter referred to as the "particle method". Each particle was assigned a user-prescribed energy content and release rate. While this method was computationally simple and inexpensive, it lacked the necessary physics to describe underventilated fire scenarios. The severest restriction of the model was that each particle required a user-prescribed fuel burn-out time, which has been characterized for well-ventilated fires but not for under-ventilated fires. A second restriction was that the fuel transport was purely convective, neglecting the small-scale diffusive processes near the flame. A third restriction was that the model did not account for the effect of oxygen depletion on the burning rate, a very important consideration for underventilated fire scenarios.

To better model realistic fire scenarios, a better combustion model was needed; but one that was consistent with the relatively large length and time scales afforded by typical computing platforms. The fast chemistry assumption inherent in the particle method could be maintained, but better transport phenomena were needed. A natural candidate for the job was the mixture fraction approach. The transport equations for the major gas species can be combined into a single equation for a conserved scalar known as the mixture fraction [3]. This quantity is defined as the fraction of the fluid mass that originates as fuel and, from it, mass fractions for all other species can be derived based on semiempirical state relationships. Typically, a mixture fraction-based combustion model assumes that the reaction is taking place on an infinitely thin flame sheet where both the fuel and oxygen concentrations go to zero. However, since we wish to avoid the expense of 
resolving the flow field at length scales fine enough to capture the actual flame sheet location, the traditional mixture fraction-based model is modified to allow for a reaction zone of finite thickness. These modifications preserve the original chemical equation for the combustion process as well as provide a framework for the inclusion of minor combustion species.

In addition to an improved treatment of the combustion processes, it was necessary to improve the radiation transport algorithm to handle phenomena such as flashover. Solution of the radiation transport equation requires determining emission, transport, and absorption properties over a wide range of infrared frequencies. Plus, the instantaneous nature of radiation transport requires that every computational cell have knowledge of the conditions in every other cell. As with the combustion model, it is possible to create a radiation transport model that tracks the emission, transport, and absorption of many frequencies of infrared light. However, such an approach is very time consuming and memory intensive. One typical simplification is to assume a gray gas and solve for only one frequency. This method still requires some form of coupling of every grid cell to every other grid cell to properly solve for attenuation. In the original version of FDS, a simple Monte-Carlo ray tracing method was used. This model was easy to implement and worked well for small fires. However, as with the particle method, this radiation model did not function well for underventilated scenarios. Thus, a finite volume radiation model [4] was added to FDS.

In the present paper, the mixture fraction-based combustion model and the finite volume radiation heat transfer model are described. Comparisons between the new and old algorithms will be performed for a variety of test cases, demonstrating the improvements added by the new routines. These test cases include a simple fire plume, a small compartment fire, and a fullscale multi-compartment fire.

\section{IMPROVEMENTS TO FDS}

\section{Mixture Fraction Combustion Model}

The Fire Dynamics Simulator solves the "low Mach number" form of the Navier-Stokes equations [5] for a multiple species fluid. These equations are obtained by filtering out pressure waves from the Navier-Stokes equations, resulting in a set of conservation equations valid for low-speed, buoyancy driven flow. These equations allow for large variations in density but not pressure. These equations are discretized in space using second order central differences and in time using an explicit, second order, predictor-corrector scheme. 
For very small-scale fires, such as a small diffusion flame burner, it is feasible to create a simulation capable of being run on a modestly powered computing platform that is detailed enough in both length scales and time scales to directly capture the combustion processes. However, for the largescale problems of interest to the fire safety community, this is not feasible. A typical compartment fire involves length scales of meters and time scales of minutes. To create a simulation of a typical compartment fire at the resolution of a Bunsen burner could be done with an extremely powerful supercomputer; however, this would be of little practical use. Instead we must approximate the combustion process in both space and time.

One simple method of coupling the combustion process with the flow field is to track three species: fuel, oxygen, and nitrogen. Since the time scales of the convective processes are much longer than the time scales of the combustion processes, infinite reaction rate chemistry can be assumed. Note, however, that this method requires solving for three species and that more species would be required to handle combustion products.

The observation can be made, however, that to track both fuel and oxygen when assuming an infinite reaction rate is redundant if the local temperature is not considered. Since neither fuel nor oxygen can coexist under those assumptions, if fuel is present there can be no oxygen and viceversa. Thus, the above method could be simplified further by replacing all the species with a single conserved scalar that represents the amount of fuel or oxygen present in any given location.

One scalar parameter that can be used to represent the local concentration of fuel or oxygen is the mixture fraction. If $Y_{\mathrm{O}_{2}}^{\infty}$ is defined as the ambient oxygen mass fraction and $Y_{F}^{I}$ the fuel mass fraction in the fuel stream, then the mixture fraction, $Z$, is defined as [6]:

$$
Z=\frac{s Y_{F}-\left(Y_{\mathrm{O}_{2}}-Y_{\mathrm{O}_{2}}^{\infty}\right)}{s Y_{F}^{I}+Y_{\mathrm{O}_{2}}^{\infty}} ; \quad s=\frac{v_{\mathrm{O}_{2}} w_{\mathrm{O}_{2}}}{v_{F} w_{F}}
$$

What the mixture fraction represents in Equation (1) can be seen in Equations (2) and (3). Equation (2) below gives the chemical reaction for the combustion of a generic hydrocarbon fuel.

$$
\mathrm{C}_{x} \mathrm{H}_{y}+\left(x+\frac{y}{4}\right)\left(\mathrm{O}_{2}+3.76 \mathrm{~N}_{2}\right) \rightarrow x \mathrm{CO}_{2}+\frac{y}{2} \mathrm{H}_{2} \mathrm{O}+\left(x+\frac{y}{4}\right) 3.76 \mathrm{~N}_{2}
$$

In a simulation of the combustion of such a fuel, at any point in the computational domain, the ideal stoichiometric conditions shown in Equation (2) will not be present as either fuel or oxygen will be in excess. The reaction for this is shown in Equation (3) below where $\zeta$ is a multiplier 
of the oxygen term to account for the relative amounts of fuel and oxygen and it varies from 0 to $\infty$.

$$
\begin{gathered}
\mathrm{C}_{x} \mathrm{H}_{y}+\xi\left(x+\frac{y}{4}\right)\left(\mathrm{O}_{2}+3.76 \mathrm{~N}_{2}\right) \rightarrow \operatorname{Max}[0,1-\xi] \mathrm{C}_{x} \mathrm{H}_{y}+\operatorname{Min}[1, \xi] x \mathrm{CO}_{2} \\
+\operatorname{Min}[1, \xi] \frac{y}{2} \mathrm{H}_{2} \mathrm{O}+\operatorname{Max}[0, \xi-1]\left(x+\frac{y}{4}\right) \mathrm{O}_{2}+\xi\left(x+\frac{y}{4}\right) 3.76 \mathrm{~N}_{2}
\end{gathered}
$$

The two terms on the left hand side will yield the mixture fraction if the definition in Equation (1) is applied. However, since the mixture fraction assumes infinitely fast chemistry, what is present in the computational domain is the right hand side of Equation (3). Thus the mixture fraction at all points in the computational domain, in essence represents a 'postcombustion' value, i.e., only products are present at any location in the computational domain.

Using Equation (1), the mass fractions of the products in Equation (3) can be plotted as a function of $Z$. As $\zeta$ varies from $\infty$ to $0, Z$ will vary from 0 to 1 , and a series of state relationships for the species can be expressed in terms of the mixture fraction. In this manner, the mixture fraction can be used to represent many species in the simulation. It is important to note that minor species such as carbon monoxide or soot (smoke) can be included in the mixture fraction state relationships if their production can be defined in terms of the mixture fraction. For example, if the molar production of soot, which can be assumed to be carbon, and $\mathrm{CO}$ is assumed to be proportional to the molar production of $\mathrm{CO}_{2}$ where $\chi_{\mathrm{S}}$ and $\chi_{\mathrm{CO}}$ are the respective molar production ratios, then Equation (4) results; this is the manner in which FDS v2 accounts for $\mathrm{CO}$ and soot formation. If the fuel is assumed to be propane and $\chi_{\mathrm{S}}$ and $\chi_{\mathrm{CO}}$ are defined respectively as 0.15 and 0.1 , chosen purely for purposes of illustration, the corresponding state relations are shown in Figure 1. However, FDS is not truly predicting $\mathrm{CO}$ or soot formation as in fact $\mathrm{CO}$ and soot production is a much more complex phenomena that can be modeled by the mixture fraction as implemented.

$$
\begin{gathered}
\mathrm{C}_{x} \mathrm{H}_{y}+\xi\left(\frac{x\left(1+\frac{1}{2} \chi_{\mathrm{CO}}\right)}{1+\chi_{\mathrm{S}}+\chi_{\mathrm{CO}}}+\frac{y}{4}\right)\left(\mathrm{O}_{2}+3.76 \mathrm{~N}_{2}\right) \rightarrow \operatorname{Max}[0,1-\xi] C_{x} H_{y} \\
+\operatorname{Min}[1, \xi]\left(\frac{x}{1+\chi_{\mathrm{S}}+\chi_{\mathrm{CO}}}\right) \mathrm{CO}_{2}+\operatorname{Min}[1, \xi] \frac{y}{2} \mathrm{H}_{2} \mathrm{O}+\operatorname{Min}[1, \xi]\left(\frac{x \chi_{\mathrm{CO}}}{1+\chi_{\mathrm{S}}+\chi_{\mathrm{CO}}}\right) \mathrm{CO} \\
+\operatorname{Min}[1, \xi]\left(\frac{x \chi_{\mathrm{S}}}{1+\chi_{\mathrm{S}}+\chi_{\mathrm{CO}}}\right) \mathrm{C}+\operatorname{Max}[0, \xi-1]\left(x+\frac{y}{4}\right) \mathrm{O}_{2}+\xi\left(x+\frac{y}{4}\right) 3.76 \mathrm{~N}_{2}
\end{gathered}
$$




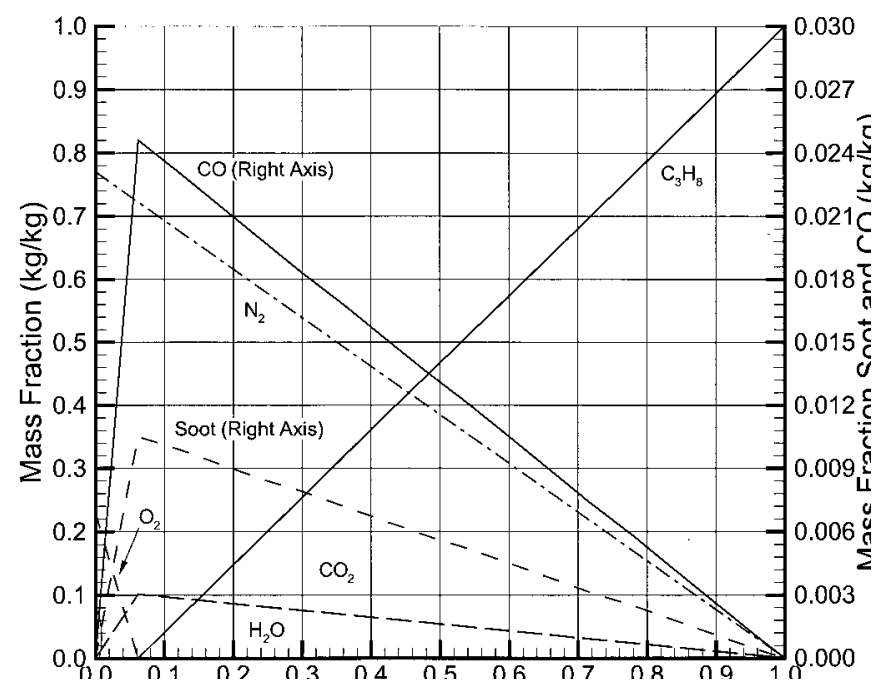

Figure 1. Mixture fraction state relationships for propane assuming constant production of soot and $\mathrm{CO}$ at $0.15 \mathrm{~mol}$ Soot $/ \mathrm{mol} \mathrm{CO}_{2}$ and $0.10 \mathrm{~mol} \mathrm{CO} / \mathrm{mol} \mathrm{CO}_{2}$.

With this representation, the flame sheet is defined to exist at the point where both fuel and oxygen disappear as products. The mixture fraction corresponding to this point is designated $Z_{F}$ and this point is equivalent to the reaction shown in Equation (2). This region is a two-dimensional surface and, for larger-scale simulations, is difficult to resolve. To implement the mixture fraction, an expression for the local heat release rate as a function of the mixture fraction must be developed.

This is done rather simply. Combustion of fuel consumes oxygen. Since the mixture fraction yields information about the local oxygen concentration, we need only determine an expression for the oxygen consumption rate based on the mixture fraction. Then, using the heat of combustion yields the local heat release rate. Consider the following two transport equations for the conserved scalar $Z$ and for oxygen:

$$
\begin{aligned}
\rho \frac{D Z}{D t} & =\nabla \times \rho D \nabla Z \\
\rho \frac{D \mathrm{O}_{2}}{D t} & =\nabla \times \rho D \nabla Y_{\mathrm{O}_{2}}+\dot{m}_{\mathrm{O}_{2}}^{\prime \prime \prime}
\end{aligned}
$$

The derivatives for oxygen in Equation (6) are expressed in terms of mixture fraction using the chain rule, diffusion is assumed constant with 
respect to species, and Equation (5) is multiplied by $d Y_{O_{2}} / d Z$.

$$
\begin{aligned}
& \rho \frac{d Y_{\mathrm{O}_{2}}}{d Z} \frac{D Z}{D t}=\frac{d Y_{\mathrm{O}_{2}}}{d Z} \nabla \times \rho D \nabla Z \\
& \rho \frac{d Y_{\mathrm{O}_{2}}}{d Z} \frac{D Z}{D t}=\nabla \times \rho D \frac{d Y_{\mathrm{O}_{2}}}{d Z} \nabla Z+\dot{m}_{\mathrm{O}_{2}}^{\prime \prime \prime}
\end{aligned}
$$

Equation (7) is subtracted from Equation (8).

$$
-\dot{m}_{\mathrm{O}_{2}}^{\prime \prime \prime}=\nabla \times \rho D \frac{d Y_{\mathrm{O}_{2}}}{d Z} \nabla Z-\frac{d Y_{\mathrm{O}_{2}}}{d Z} \nabla \times \rho D \nabla Z
$$

At first glance, Equation (9) appears to be rather complex. However, its meaning can be understood simply. It can be seen in Figure 1 that $d Y_{\mathrm{O} 2} / d Z$ at any point in the computational domain is either zero or a constant depending on which side of $Z_{F}$ one is located. If the computational domain is divided into the two regions of $Z \leq Z_{F}$ and $Z>Z_{F}$, then Equation (9) can be integrated over these two regions while applying the divergence theorem. Since the $d Y_{\mathrm{O} 2} / d Z$ term will be zero in the region $Z>Z_{F}$, this region can be ignored. The end result is the mass loss rate of oxygen as a function of the mixture fraction diffusion across the flame surface as shown below:

$$
\dot{m}_{\mathrm{O}_{2}}^{\prime \prime}=-\frac{d Y_{\mathrm{O}_{2}}}{d Z} \rho D \nabla Z \times\left.\hat{n}\right|_{Z=Z_{F}}
$$

Since oxygen is a function of only the mixture fraction, this is equivalent to saying that the global heat release rate is a function of the oxygen gradient across the flame sheet. In fact, due to the diffusion constant in the expression and the assumption of infinite reaction rates, Equation (10) states that the heat release rate is due solely to the diffusion of oxygen across the flame, which is given by the hydrodynamic solver. Since we do not know a priori the location and orientation of the flame sheet, only Equation (9) is useful for a numerical scheme. However, to save computational time, Equation (9) needs only be evaluated at the cell interfaces where one cell is greater than $Z_{F}$ and one cell is less than $Z_{F}$.

\section{Finite Volume Radiation Model}

FDS v1 computes radiative fluxes with a Monte-Carlo style ray-tracing from the burning particles to the walls. The model neglects gas-to-gas interactions and wall-to-wall interactions, and, thus, performs poorly for compartment scenarios with very hot gas layers or surfaces as would occur 
in a compartment approaching flashover. The original ray-tracing radiation model was changed to a Finite Volume Method [4]. This method is derived from the radiative transport equation (RTE) for a nonscattering gray gas [7].

$$
\hat{s} \times \nabla I(\hat{x}, \hat{s})=\kappa(\hat{x})\left[I_{b}(\hat{x}, \hat{s})-I(\hat{x}, \hat{s})\right]
$$

$I(\hat{x}, \hat{s})$ is the radiation intensity, $I_{b}(\hat{x}, \hat{s})$ is the blackbody radiation intensity, $\kappa(\hat{x})$ is the absorption coefficient, and $\hat{s}$ is the unit normal direction vector. Implementing this equation in a large eddy simulation requires determining how to specify the absorption coefficient, $\kappa$, and how to create the source term, $I_{b}(\hat{x}, \hat{s})$. For the length scales of interest to the fire research community, the specification of both terms in a computationally simple manner is nontrivial.

The source term is typically given by the Stefan-Boltzman law [7]:

$$
I_{b}(\hat{x}, \hat{s})=\frac{\sigma T(\hat{x})^{4}}{\pi}
$$

Where $T(\hat{x})$ is the local temperature and $\sigma$ is the Stefan-Boltzman constant. Since the cell temperature represents the average temperature over the entire volume of the cell, in the case of a computational cell without combustion, the cell temperature is a reliable indicator of the radiative emission. However, in the case of a cell with combustion occurring, where the average temperature is not necessarily the flame temperature, this may not hold true. For most computations, the volume of a grid cell is much larger than the volume within the cell where combustion would actually be taking place. With the fourth power dependence on temperature, this will result in greatly under predicting the source term in cells with combustion. Thus, the source term will need to be corrected in these cells. One manner of correcting the source term is to simply add a fraction of the cell's heat release, for example a typical value of $35 \%$ [8] for a coarse grid, to the source term. FDS v2 uses a simple rule to adjust the source term. If the calculated emission from a combusting cell is less than a user specified fraction of the local heat release rate, with a default of $35 \%$, that calculated term is replaced with the user specified fraction.

$\kappa(\hat{x})$ is a function of the local concentrations of absorbing species $\left(\mathrm{CO}_{2}\right.$, $\mathrm{CO}, \mathrm{H}_{2} \mathrm{O}$, Soot, and fuel), the local temperature, and a pathlength over which the radiation travels [9]. The species concentrations can be obtained from the mixture fraction and the temperature can be obtained from the hydrodynamics solver. There is no simple way, however, to evaluate the pathlength. In reality, this would involve determining, for each grid cell, the 
potential travel distance through the computational domain for all possible directions of travel, a computationally expensive process. Instead a pathlength is assumed at the onset of a simulation based on the overall size of the computational domain. Then an array of values of $\kappa$ is created as a function of temperature and mixture fraction by using RADCAL with the assumed pathlength [10]. $\kappa(\hat{x})$ is then found by table lookup.

To solve the RTE, the finite volume method first divides all possible direction vectors, $\hat{s}$, into a number of spherical angles, typically around 100 , which results in one RTE for each angle grouping. The RTE is then integrated over each cell, with cell indices of $i, j$, and $k$, resulting in the following equation:

$$
\sum_{m=1}^{6} A_{m} I_{m}^{L} \int_{\Omega^{L}} \hat{s} \times \hat{n}_{m} d \Omega=\kappa_{i j k}\left(I_{b, i j k}-I_{i j k}^{L}\right) V_{i j k} d \Omega^{L}
$$

This RTE is solved for each grid cell and for each angle. For each angle, $L$, the upwind direction is determined and the appropriate boundary condition used to determine the upwind flux. For example, if the current angle were a vector pointing downward to the right and to the back of the domain, the upwind direction would be the upper, front, left corner. The flux into the domain from the three cells bounding that corner would be used for the boundary condition. The downwind fluxes are then determined by marching through the domain in the downwind direction. The net radiant intensity is found by summing over all angle groupings. To save computational time, only a subset of the angle groupings is updated at each time step, typically about every fifth angle.

\section{COMPARISONS OF FDS V1 TO FDS V2}

The new version of FDS with the mixture fraction combustion and finite volume radiation model has been tested with a variety of fire scenarios. A few are shown here and compared with version 1 with its Lagrangian particle model and ray-tracing model.

\section{Pool Fire}

Simulations of a $0.2 \mathrm{~m}$ diameter pool fire were performed for three different fire sizes: 15,30 , and $60 \mathrm{~kW}$. The cell size over the burner was $0.024 \mathrm{~m}$, the burner was defined in FDS as a square, and the default FDS fuel chemistry for propane was used. This grid size was chosen to meet the requirements of the flow solver, which requires that the grid be of the order 
of $10 \%$ of the plume length scale [5]. The $60 \mathrm{~kW}$ plume was also simulated using a denser grid with a grid size of $0.013 \mathrm{~m}$. Once a steady-state was reached, time averages were taken of the centerline temperatures and vertical velocities. These were compared with temperatures and velocities calculated using McCaffrey's correlation [8].

Figure 2 illustrates the major advantage that arises from the use of the mixture fraction as opposed to the Lagrangian particle model. Since the Lagrangian particles are transported solely by the velocity field, and since the normal velocity at a surface is essentially zero, it takes the particles time to move away from the burner. As a result, a large fraction of the particle's heat is emitted incorrectly near the burner surface. The requirement that combustion occurs on the $Z_{F}$ surface results in the heat being released towards the edge of the plume where the oxygen is located. In contrast, the Lagrangian particles, which move towards the center of the plume due to the radial entrainment velocity, release their heat towards the plume center.

Figures 3 and 4 display respectively the centerline temperature and velocity predictions of the $30 \mathrm{~kW}$ simulation versus McCaffrey's correlation. FDS results are shown time-averaged over a period of approximately $30 \mathrm{~s}$. The results of the other simulations were similar and are omitted for brevity. Far-field temperature predictions for both methods are the same and agree
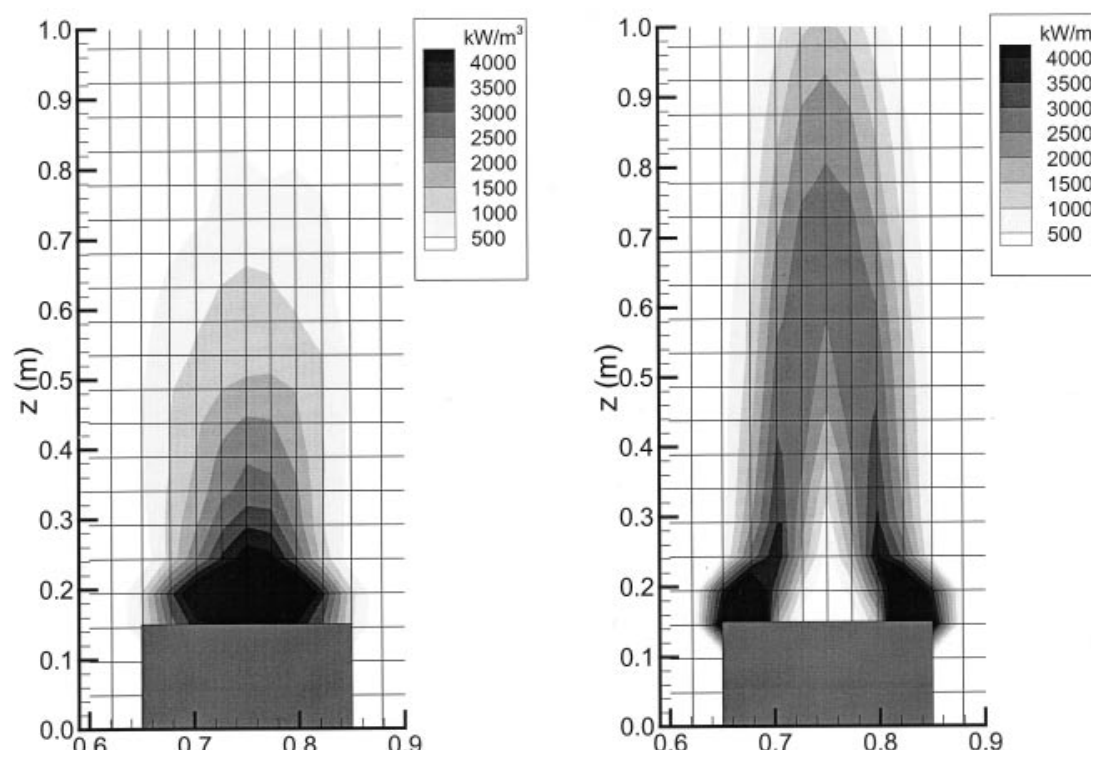

Figure 2. Comparison of heat release rate contours for FDS v1 (Left) and FDS v2 (Right) for a $0.2 \mathrm{~m}$ square burner, $60 \mathrm{~kW}$ pool fire. 


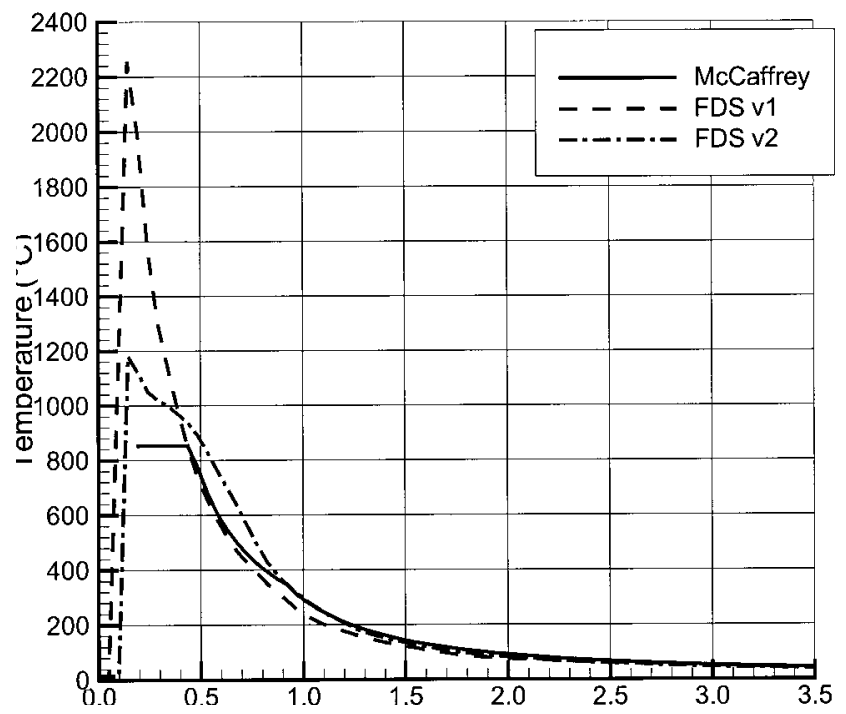

Figure 3. Centerline temperature profile for a $30 \mathrm{~kW}$ pool fire: FDS v1, FDS v2, and McCaffrey's correlations.

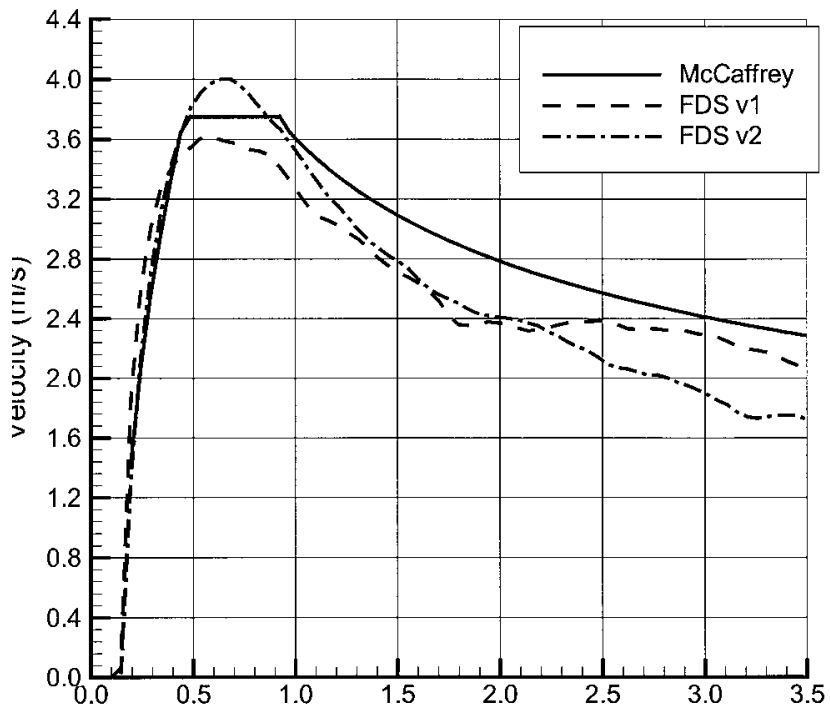

Figure 4. Centerline velocity profile for a $30 \mathrm{~kW}$ pool fire: FDS v1, FDS v2, and McCaffrey's correlations. 
with McCaffrey's correlation. This is to be expected since buoyancy forces drive the far field calculation, which depends more upon the total heat release rate rather than its spatial distribution. Temperatures for the mixture fraction method are significantly better in the near field. The temperature plots clearly show the improvement in the geometric distribution of the heat release. Velocity predictions show a small improvement relative to McCaffrey's correlation for the mixture fraction model. The mixture fraction method better captures the near-field velocity profile as the heat release is occurring in a more realistic distribution. Thus, the near-field buoyancy forces are being better simulated with the mixture fraction model than with the Lagrangian particle method. The far field velocities are slightly worse with the mixture fraction, the reason for which is not clear. However, since the particle method does not show a smoothly decreasing centerline velocity, the mixture fraction version while not matching the end magnitude as close as the particle method, is matching the trend correctly.

\section{NIST-BFRL 40\% Reduced Scale Enclosure (RSE)}

A recent investigation at NIST attempted to determine the measurement uncertainties in the use of bare-bead and aspirated thermocouples for compartment fires [12]. As part of this investigation, natural gas and hexane fires were set inside of a $40 \%$ scale compartment based on a standard compartment in ISO-9705. A $400 \mathrm{~kW}$ natural gas fire was selected from this investigation for simulation with FDS. The compartment and the measurement locations chosen for simulation are shown in Figure 5. The gas burner was located in the center of the compartment with its top $0.15 \mathrm{~m}$ above the floor. For the simulations, the grid size was $0.04 \mathrm{~m}$ and the computational domain was extended beyond the doorway by one third of the compartment's length. The simulation results are compared with data collected during the $400 \mathrm{~kW}$ test.

Figures 6 and 7 show predicted versus measured temperatures for the two aspirated thermocouples (TC) located at $0.24 \mathrm{~m}$ and $0.80 \mathrm{~m}$ inside the front of the compartment. These were the only aspirated TCs located inside the compartment. A few observations are made from these figures:

1. At the start of the fire, both models show much faster temperature increases than measured during the test. This is probably due in part to numerical diffusion of heat, since a relatively coarse grid was used.

2. For the upper TC, the particle method over predicts the temperature increase by $60 \%$ at this location whereas the new model over predicts the measured value by $20 \%$. The over prediction by the particle method is primarily a result of the radiation model, which does not calculate 


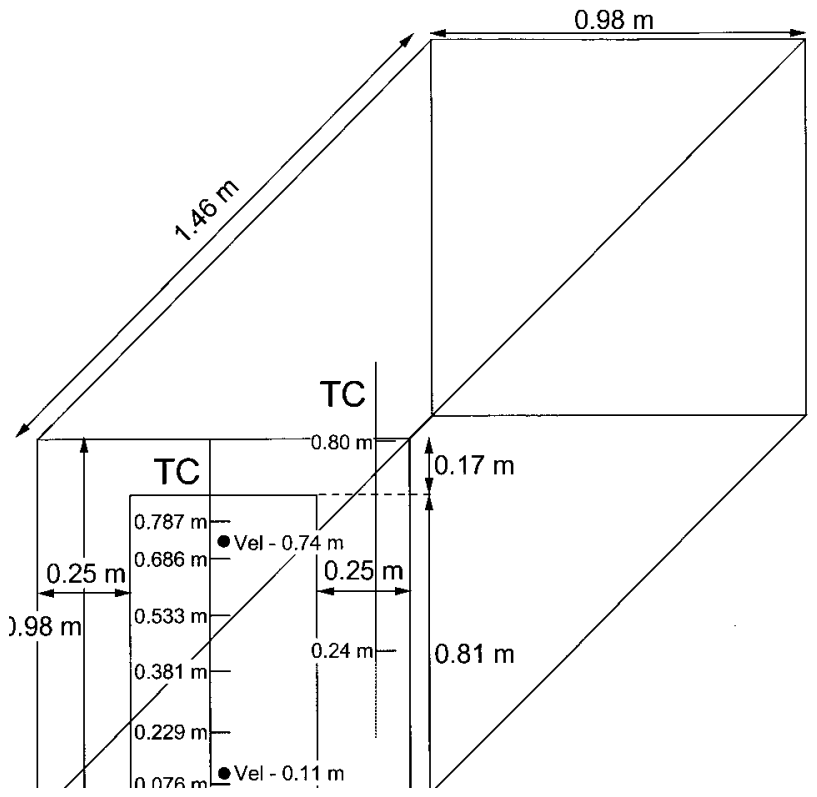

Figure 5. NIST 40\% reduced scale enclosure showing dimensions and locations of instrumentation.

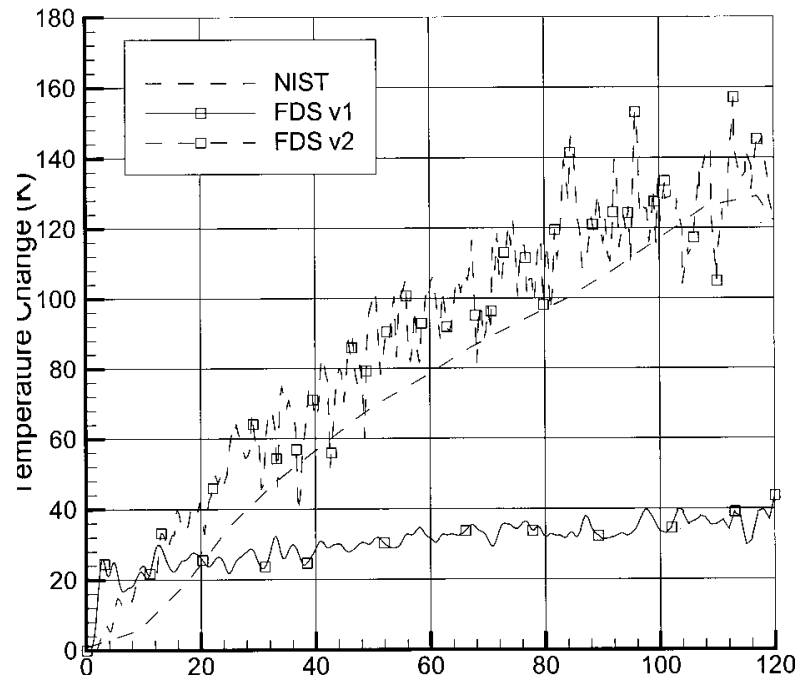

Figure 6. FDS v1 and FDS v2 predictions for NIST 40\% RSE lower layer temperature (front corner at $0.24 \mathrm{~m}$ above the floor) for a $400 \mathrm{~kW}$ fire. Plotted as temperature change from ambient. 


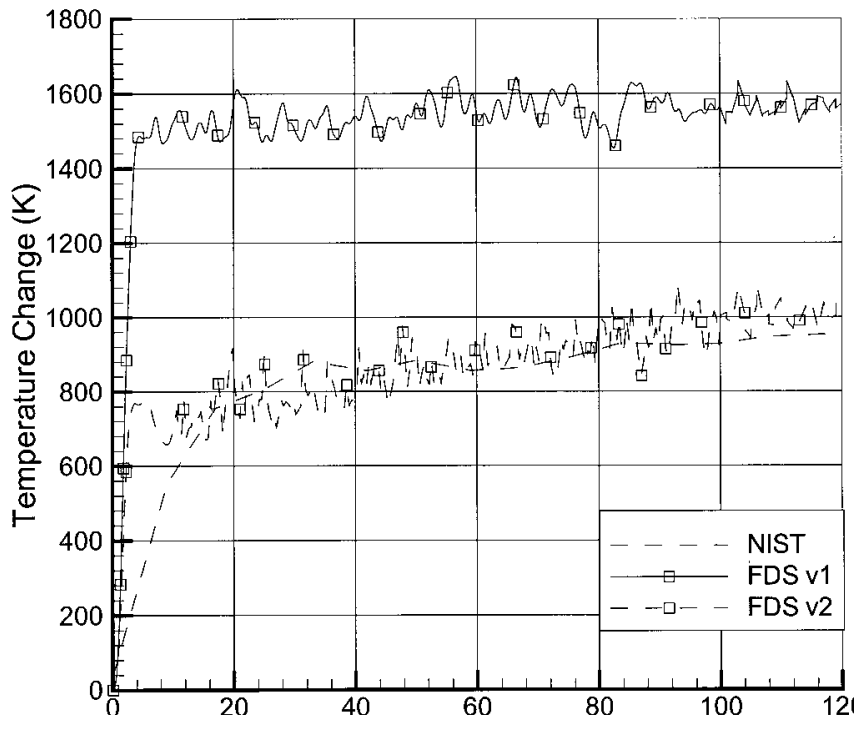

Figure 7. FDS v1 and FDS v2 predictions for NIST 40\% RSE upper layer temperature (front corner at $0.80 \mathrm{~m}$ above the floor) for a $400 \mathrm{~kW}$ fire. Plotted as temperature change from ambient.

radiative transfer from the ceiling layer to the floor. The over prediction of the new model has two possible contributions. One, is that too much heat is being released inside the compartment. This could result from an underprediction of the flame lengths due to the grid resolution enhancing mixing, and it also results from the assumption of complete combustion which is not the case for a $400 \mathrm{~kW}$ fire in a compartment of that size. During the actual test, a significant portion of the heat release was outside the compartment, whereas FDS did not predict as large a flame surface. Two, the new models may be under predicting the wall and radiative losses from the hot gas.

3. For the lower TC, after $40 \mathrm{~s}$, the particle method predictions lie well below the measured data whereas FDS v2 predictions agree well with the measurements over this time period. These results are primarily due to the different radiation models.

Figures 8 and 9 plot the predicted and measured velocities in the doorway. The measurements were made by bi-directional probes. In the lower layer, the particle method under predicts the velocity by $15 \%$ whereas the mixture fraction model over predicts the measured data by $40 \%$. In the upper layer, it is observed that both FDS versions under predict the velocity at this 


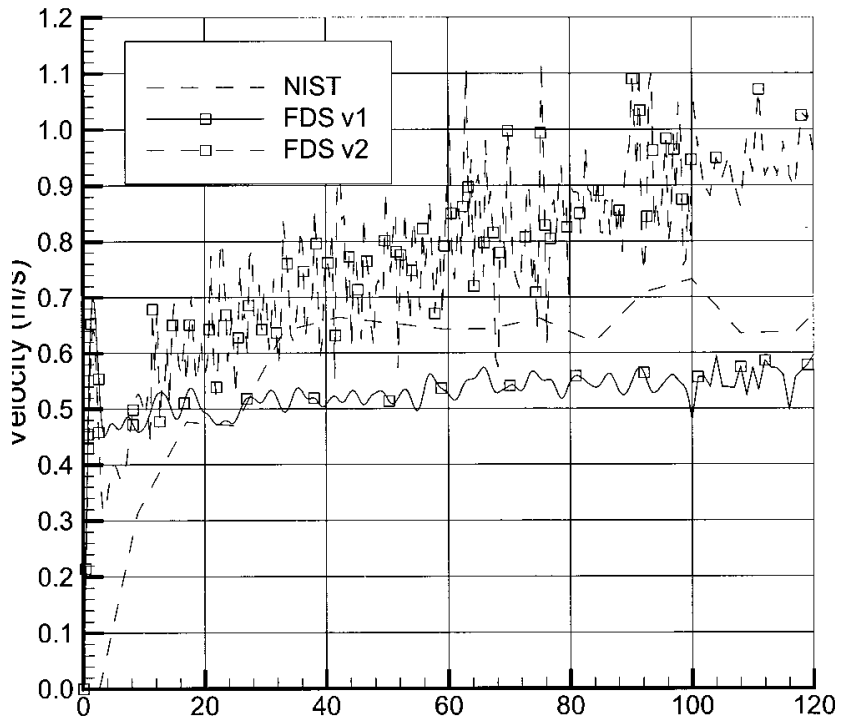

Figure 8. FDS v1 and FDS v2 predictions for NIST 40\% RSE lower layer doorway centerline velocity ( $0.1 \mathrm{~m}$ above the floor) for a $400 \mathrm{~kW}$ fire.

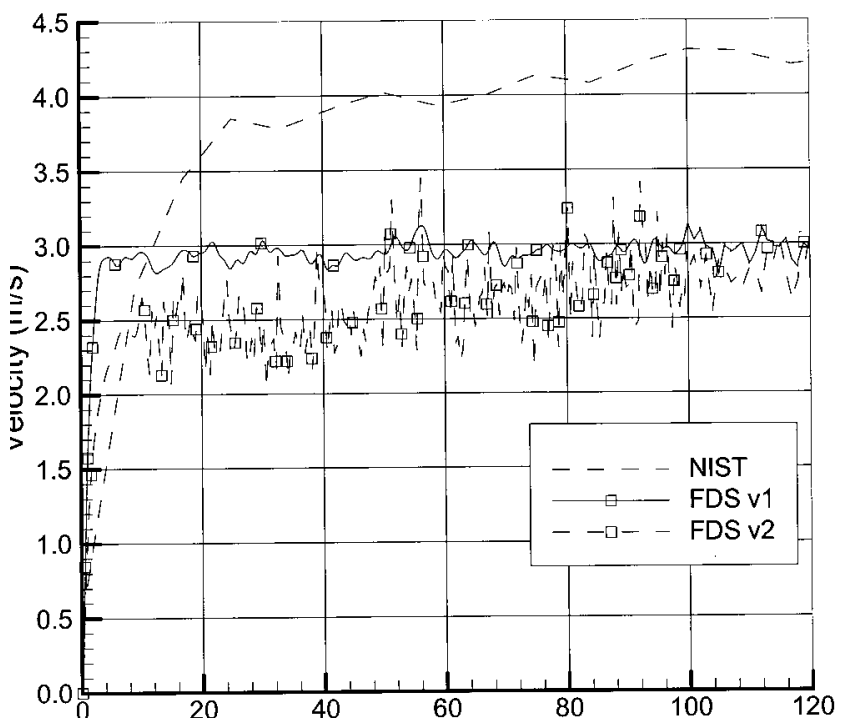

Figure 9. FDS v1 and FDS v2 predictions for NIST 40\% RSE upper layer doorway centerline velocity $(0.07 \mathrm{~m}$ below the top of the doorway) for a $400 \mathrm{~kW}$ fire. 
location by $31 \%$ for the particle method and by $35 \%$ for the mixture fraction. Again, it is observed that both versions of FDS show a faster initial transient. This discrepancy has two possible contributions. The first may be that the nodding results in smearing the doorway massflow profile resulting in lower velocities at the measurement location. The second is that FDS may be predicting a slightly different shape for the velocity profile which would result in a difference between the experiment and the simulation. Without further resolution in the data, the exact cause of the discrepancy cannot be identified.

The final graphical comparisons for this scenario are Figures 10 and 11, which depict the temperature and velocity profiles in the doorway at $120 \mathrm{~s}$. The temperature profile results clearly show that the mixture fraction predictions are closer to the observed temperature profile than the particle method. Both versions predict a somewhat larger upper layer than indicated by the data which could be due to the grid resolution. The velocity profiles show both versions predicting similar profiles, though the mixture fraction method predicts a slightly smaller lower layer. The pointwise prediction errors look more reasonable when the entire profile is considered.

Lastly, species predictions made by the mixture fraction method are compared to values measured in the top center of the door in the vicinity of the uppermost thermocouple. $\mathrm{CO}_{2}$ and $\mathrm{O}_{2}$ concentrations measured during

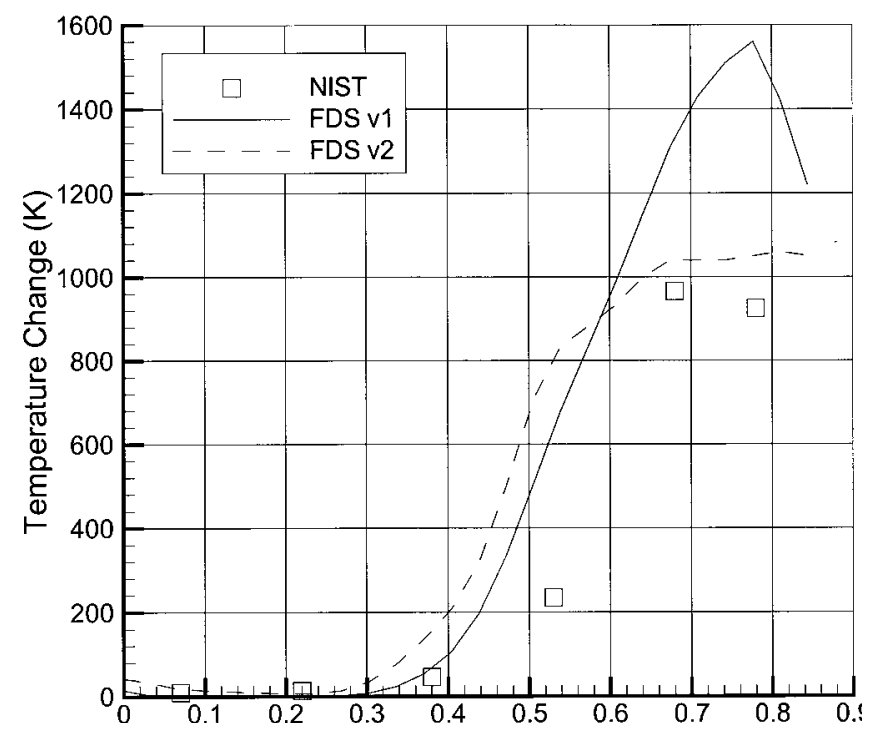

Figure 10. FDS $v 1$ and FDS v2 predictions for NIST $40 \%$ RSE doorway centerline temperature profile for a $400 \mathrm{~kW}$ fire at $120 \mathrm{~s}$. Plotted as temperature change from ambient. 


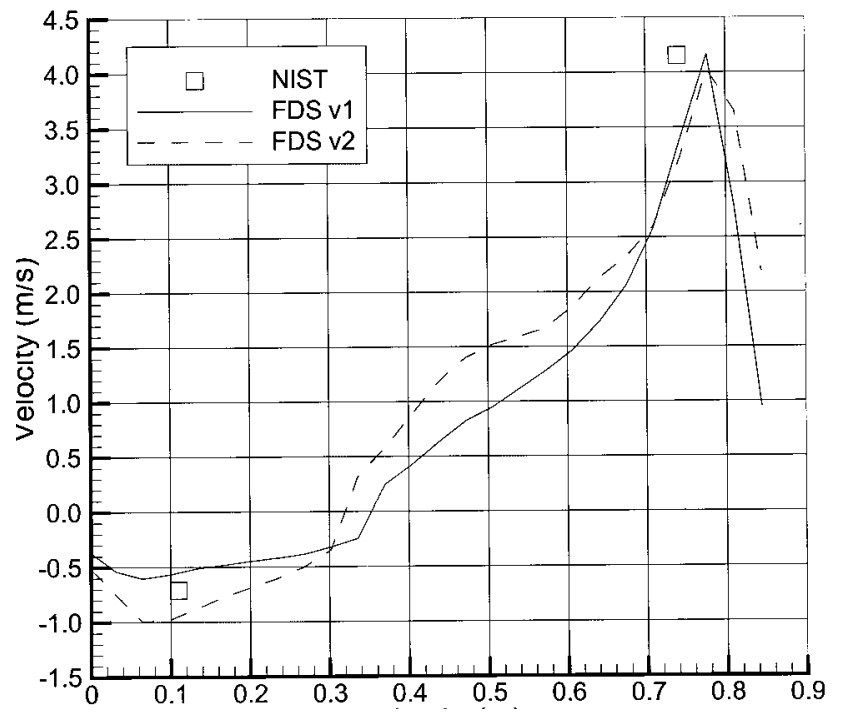

Figure 11. FDS v1 and FDS v2 predictions for NIST 40\% RSE doorway centerline velocity profile for a $400 \mathrm{~kW}$ fire at $120 \mathrm{~s}$.

the test were 8.7 and $0.2 \%$, respectively. FDS predicted respectively 9.0 and $0.0 \%$. These values indicate that FDS with mixture fraction is capable of making good predictions of major species concentrations. However, they also indicate a weakness of the current mixture fraction implementation. There were flames out the doorway during this test, indicating the presence of yet unreacted fuel and oxygen. The mixture fraction model as implemented assumes infinitely fast chemistry and precludes the simultaneous presence of fuel and oxygen. Thus, combustion inefficiencies that occur during underventilated fires are not completely captured. See comment discussion of Figures 6 and 7.

\section{HDR Propane Fire Test}

The HDR test facility was the containment building from a decommissioned nuclear reactor in Germany. The facility was a cylinder $20 \mathrm{~m}$ in diameter and $50 \mathrm{~m}$ in height and was topped by a $10 \mathrm{~m}$ radius hemispherical dome. The facility had eight levels and over 60 compartments. Multiple vertical flowpaths were present in the form of two axially located sets of equipment hatches, two staircases, and an elevator shaft. The total free air volume in the facility was $11,000 \mathrm{~m}^{3}$ of which the dome contained $4800 \mathrm{~m}^{3}$ [13]. The facility was used for a number of studies of different types of 
containment building threats including earthquakes, blowdowns, plane crashes, and fires. The fire study consisted of seven test groups using different fuels in different locations [14].

The test simulated in this paper is test T51.23, a $1 \mathrm{MW}$ propane fire test performed in 1986 on the 4th level of the facility in a series of specially constructed compartments [14,15], see Figure 12, which were lined with fire brick to prevent damage to the facility. Hatches on the 4th level were open to the levels above to provide an exhaust path to the dome for combustion products. For this test, five propane gas burners located near the outer wall of the facility were fed propane premixed with $10 \%$ excess air. The facility was instrumented with numerous velocity sensors (Pitot tubes) and thermocouples. The thermocouples were not aspirated, thus, significant errors can be expected in the temperature measurements made in the lower portion of the fire room.

The FDS simulation of this fire included the fire room and the curved hallway leading to the open hatch to the 5 th level. The resulting geometry yielded a computational domain $11.2 \mathrm{~m} \times 9.6 \mathrm{~m} \times 4.6 \mathrm{~m}$ in dimension. This region was mapped to a finite differenced volume of 108 cells $\times 96$ cells $\times 54$ cells for a total of 560,000 nodes. The resulting geometry is shown in Figure 13. Since the mixture fraction model precludes a true premixed fuelair mixture, two sets of five burners were defined for the simulation. One set of burners, located at the actual burner locations for the test, fed fuel, and the other set, located just above the actual burners, fed air. The FDS

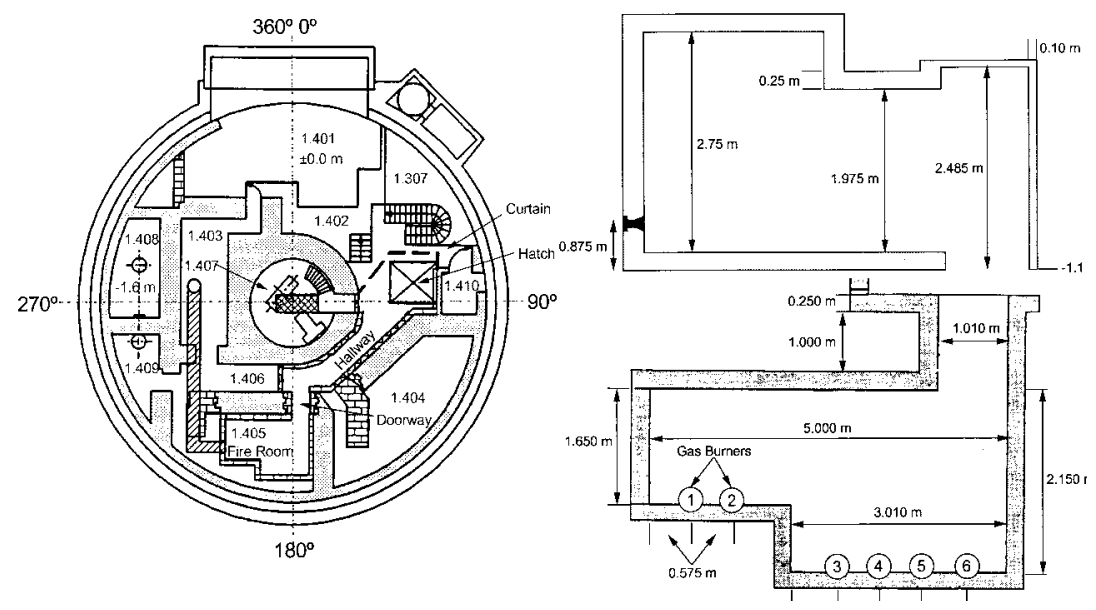

Figure 12. HDR propane fire test layout. 


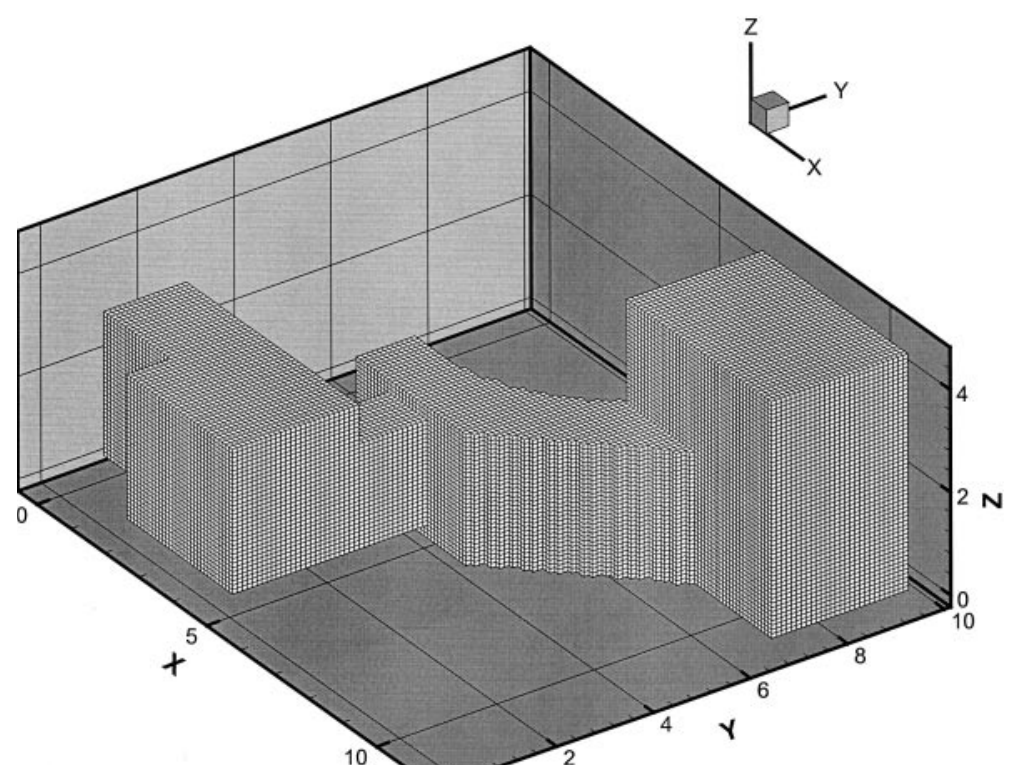

Figure 13. FDS grid for the HDR propane fire test.

simulations were run for 10 min of real time. An extensive description of the input model for this simulation can be found in Reference [15].

The first two comparisons of FDS results to HDR data, Figures 14 and 15, show the temperature rise in the fire room near the doorway at elevations $0.15 \mathrm{~m}$ above the floor and $0.2 \mathrm{~m}$ below the ceiling. Combined, these figures show the tremendous improvement in predictive capabilities for large compartment fires. The particle method, with its simple radiation model, precludes the hot upper layer from radiating heat to the floor. This results in over predicting the upper layer temperature by a factor of two and not predicting any noticeable change in the lower layer temperature. The mixture fraction version of FDS, with its improved radiation model, does much better at predicting the upper layer to lower layer heat transfer. It now under predicts the upper layer temperatures by less than $5 \%$ and predicts a temperature rise in the lower layer indicating that the floor is heating up and convecting heat to the incoming gas in the lower layer. As the thermocouples in the fire room have a direct line of site to the gas burners, they indicate a measured temperature higher than the actual gas temperature. For the upper layer, this is not likely to be a large error percentage, but it will be for the lower layer. Thus, with the mixture fraction and finite volume radiation, FDS is likely performing better than indicated by these plots. Both versions of FDS show a much faster initial transient, 


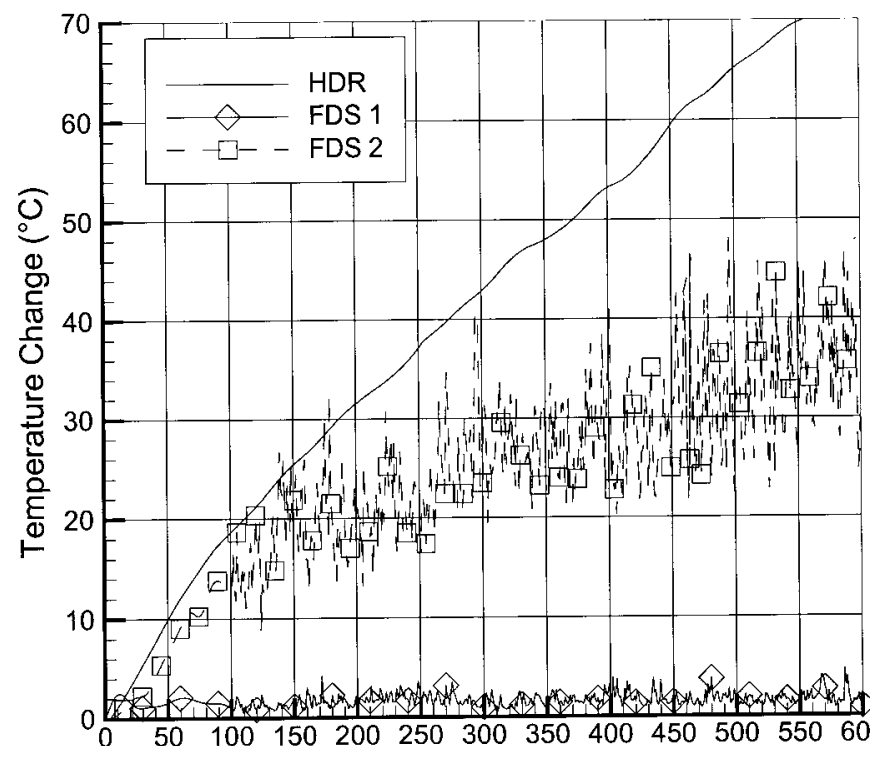

Figure 14. FDS $v 1$ and FDS v2 predictions for HDR fire room temperature rise $0.15 \mathrm{~m}$ above the floor near the doorway. Plotted as temperature change from ambient.

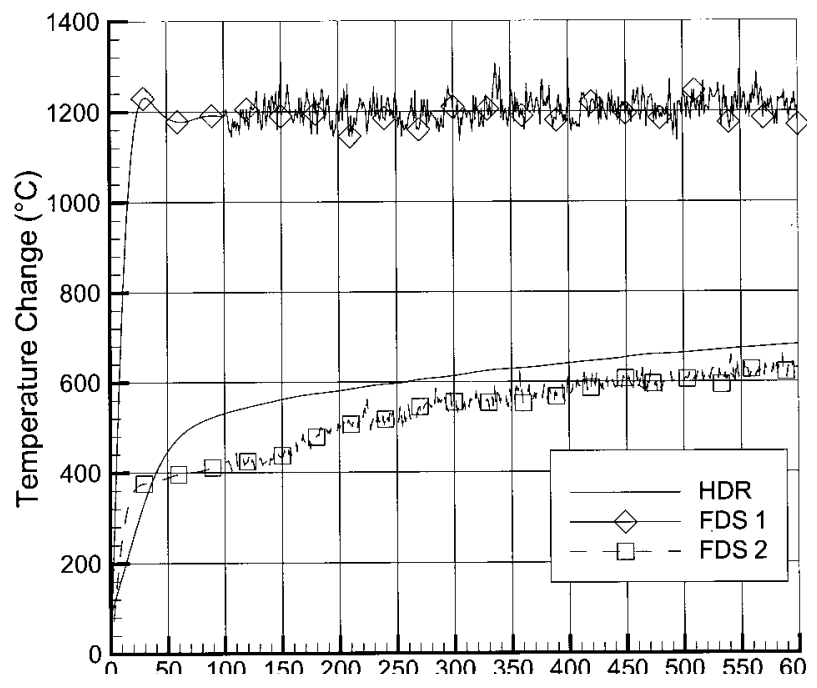

Figure 15. FDS $v 1$ and FDS v2 predictions for HDR fire room temperature rise $0.2 \mathrm{~m}$ below the ceiling near the doorway. Plotted as temperature change from ambient. 


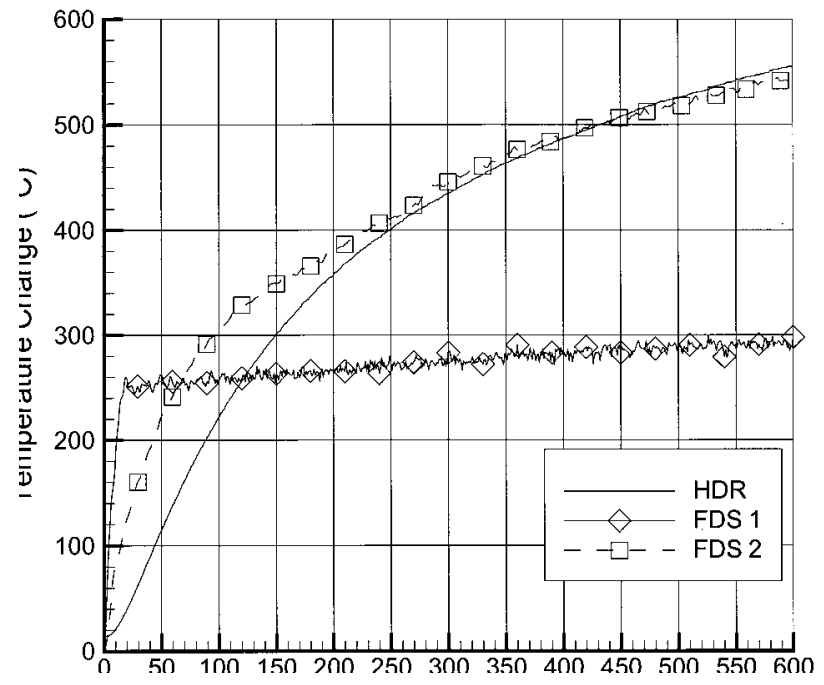

Figure 16. FDS v1 and FDS v2 predictions for HDR fire room wall temperature rise $0.6 \mathrm{~m}$ below the ceiling opposite burner \#3 near the midpoint elevation of the fire room.

however, the particle method quickly reaches steady state, whereas after $200 \mathrm{~s}$, the mixture fraction method matches the rate of temperature rise seen in the data.

The next figure, Figure 16, depicts the wall temperature change opposite Burner \#3 at $0.6 \mathrm{~m}$ below the ceiling in the upper layer of the fire room. This figure illustrates well the improvements made in modeling wall heat transfer. As in the previous two figures, the particle method shows a much faster initial transient than seen in the data. However, even though the gas temperatures are over predicted by a factor of two, the wall temperatures are under predicted by a factor of two. Again, this is primarily a result of the radiation model. The mixture fraction version on the other hand shows an initial transient that is closer, though still too fast, to that seen in the data, and at $600 \mathrm{~s}$ is predicting a surface temperature that is only $3 \%$ less than the measured data. This improvement in surface temperature prediction greatly improves the ability of FDS to predict thermal damage potential and the possible ignition of objects distant from the fire, which is critical in predicting the onset of flashover.

The last figure, Figure 17, shows the upper layer temperature change in the hallway $0.23 \mathrm{~m}$ below the ceiling approximately halfway between the fire room doorway and the region beneath the maintenance hatch to the facility's 5th level. Again it is observed that both versions show too fast of an initial transient. However, the particle method reaches a steady state 


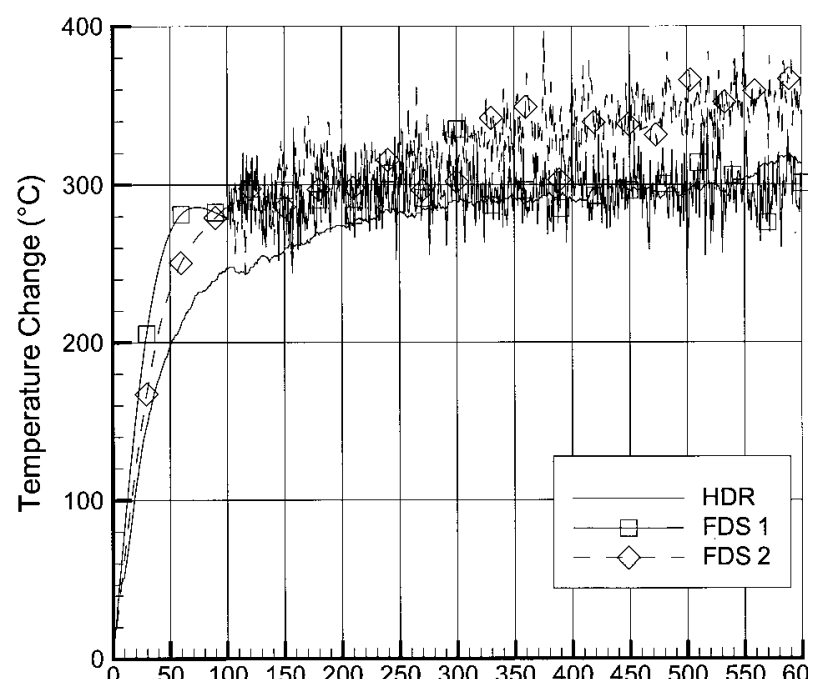

Figure 17. FDS v1 and FDS v2 predictions for HDR hallway upper layer temperature rise $0.23 \mathrm{~m}$ below the ceiling midway between fire room and hatch to 5th level.

temperature change approximately $15 \%$ lower than the mixture fraction version. This is surprising since the initial temperature change of the upper layer in the fire room was a factor of two higher. This would suggest that the heat transfer to the hallway ceiling is being greatly over predicted by the particle method. The mixture fraction version, which over predicts the hallway temperature rise by $12 \%$, is slightly under predicting the heat transfer to the ceiling, a result which is similar to that seen in the fire room wall temperature. Since radiation heat transfer plays a much smaller role in the hallway due to the lower temperatures, the improvements seen in this location are likely the result of modifications to the convective heat transfer model in FDS [1].

The final HDR comparisons are for a set of gas sensors located in the centerline of the doorway, $0.16 \mathrm{~m}$ below the doorway soffit. Four sensors were placed here, $\mathrm{CO}_{2}, \mathrm{CO}$, unburned hydrocarbons, and $\mathrm{O}_{2}$. Only the $\mathrm{CO}_{2}$ and $\mathrm{O}_{2}$ sensors generated useable data for this test. At $10 \mathrm{~min}$, the sensors indicated respective concentrations of 8.0 and $11.5 \%$ whereas mixture fraction predictions were 7.2 and $7.7 \%$. For this simulation, the mixture fraction is still predicting well the $\mathrm{CO}_{2}$ concentration at this point, but is over predicting the oxygen consumption at this point. It is not clear why this is the case, though it may result from the actual test using premixed air and fuel which cannot be directly simulated with the mixture fraction concept as implemented. 


\section{CONCLUSIONS}

A new combustion model and a new radiation model have been added to FDS v1 as part of a series of enhancements to create a new version of FDS, which has been released as $\mathrm{v} 2$. The new combustion model is a mixture fraction model modified to work on the coarse grids usually used in simulating compartment fires. This model adds the ability to track major combustion species with only a small added computational cost. The mixture fraction model may also be extended to include minor species once appropriate data concerning state relationships for compartment fires can be developed. The new radiation model allows FDS to model gas-gas and gas-surface radiation heat transfer, which was not possible in the original model.

To test the new version of FDS and to compare it with the previous release, two sets of simulations were done. The first set was a simulation of three different pool fires. Since this set involved nonventilation controlled fires that do not form hot gas layers, the results are a good comparison of predictive changes caused solely by the combustion model. The second set involved two compartment fires including a $400 \mathrm{~kW}$ fire in the NIST $40 \%$ Reduced Scale Enclosure, which was ventilation controlled and a $1 \mathrm{MW}$ fire in the HDR test facility, which was not ventilation controlled.

The plume tests clearly indicate two things. First, since both versions predict nearly the same results in the far-field, it is clear that the changes made to add the mixture fraction and finite volume radiation models, did not adversely affect the hydrodynamics solution. Second, the results illustrate well a major advantage of the mixture fraction model. Since the mixture fraction model preserves the single step chemical reaction and has the fuel as a gas rather than solid particles, the volume where combustion takes place is more realistic. With the Lagrangian particle method, combustion occurs too close to burner surface and the burner's centerline. This is not realistic, as that region in reality will contain little oxygen to support combustion. The mixture fraction model, however, has the combustion occurring near the edge of the burner. It still has numerical artifacts, which can be seen in the region of intense combustion at the burner's edge where the coarseness of the grid results in overly high mixture fraction gradients at that location.

The compartment fire simulations also show that the new version of FDS is an improvement over the particle method. Temperature predictions, especially the lower layer temperatures, are greatly improved with the new version. This is mostly a result of the new radiation model. However, there are also some minor benefits from the mixture fraction model which does account for the small changes in total moles of gas that result from combusting a hydrocarbon, which has a slight impact on the mass flow 
predictions, which in turn impacts the temperature predictions. The mixture fraction also managed to reasonably predict major species concentrations exiting the compartment. This represents a major improvement over FDS v1, which did not have this capability.

The compartment simulations indicate that further improvements could be made to the mixture fraction model. The comparison of gas concentrations in the doorway, notably the complete lack of oxygen, and the comparison of the FDS results with visual observations indicate that the combusting surface in the mixture fraction model is too small. That is, too much combustion is taking place inside the compartment. An extension of the mixture fraction model to account for combustion inefficiencies during underventilated fires might improve the prediction of the flame surface, which in turn should lead to lower upper layer temperatures. The inclusion of a reaction progress parameter would also allow for a better simulation of premixed fuels.

In conclusion, the mixture fraction combustion model and finite volume method radiation solver were successfully implemented in FDS. These improvements result in markedly improved predictive capabilities for the cases tested. However, these are not the only benefits. The mixture fraction, as a single species, through its state relationships, see Figure 1, contains information about combustion products. It is hoped that the current idealized combustion can be expanded to more realistically include minor species such as soot and $\mathrm{CO}$, e.g., by creating a two-parameter mixture fraction that includes a reaction progress variable as opposed to merely specifying a fixed $\mathrm{CO} / \mathrm{CO}_{2}$ production ratio. The new radiation model, which includes gas-to-surface and surface-to-surface radiation heat transfer enables FDS to begin making plausible predictions of object ignition times for flashover prediction. While further development could improve both models, the mixture fraction combustion model and the finite volume radiation transport model are a significant improvement over the Lagrangian particle model and the ray-tracing model.

\section{NOMENCLATURE}

$\begin{array}{ll}D \phi / D t & \text { substantial or material derivative of } \phi \\ i j k & \text { cell indices } \\ I & \text { radiation intensity }\left(\mathrm{W} / \mathrm{m}^{2}\right) \\ I_{b} & \text { radiation source term }\left(\mathrm{W} / \mathrm{m}^{2}\right) \\ \dot{m}_{i}^{\prime \prime \prime} & \text { production rate of change of species } i \text { per unit volume }\left(\mathrm{kg} / \mathrm{s} \mathrm{m}^{3}\right) \\ \dot{m}_{i}^{\prime \prime} & \text { production rate of change of species i per unit area }\left(\mathrm{kg} / \mathrm{s} \mathrm{m}^{2}\right) \\ \hat{n} & \text { normal vector }\end{array}$


oxygen mass to fuel mass ratio for stoichiometry $\left(\mathrm{kg} \mathrm{O}_{2} / \mathrm{kg}\right.$ fuel) path vector time $(s)$ temperature $(K)$ position vector $(m)$ volume $\left(\mathrm{m}^{3}\right)$ mixture fraction stoichiometric value of the mixture fraction mass fraction ( $\mathrm{kg}$ species $i / \mathrm{kg}$ gas) molecular weight of species $i(\mathrm{~g} / \mathrm{mol})$ yield of species $i$ (moles species $\mathrm{i} /$ moles fuel burned) absorptivity $(1 / \mathrm{m})$ stoichiometric coefficient of species $i$ (moles) density $\left(\mathrm{kg} / \mathrm{m}^{3}\right)$ Stefan-Boltzman constant $\left(\mathrm{W} / \mathrm{m}^{2} \mathrm{~K}^{4}\right)$ ratio of supplied air to stoichiometrically required air (moles air supplied/moles required)

\section{REFERENCES}

1. McGrattan, K. et al., Fire Dynamics Simulator (Version 2) - Technical Reference Guide, NISTIR 6783, National Institute of Standards and Technology, Gaithersburg, MD, 2001.

2. McGrattan, K. and Forney, G., Fire Dynamics Simulator (Version 2) - User's Manual, NISTIR 6784, National Institute of Standards and Technology, Gaithersburg, MD, 2001.

3. Kuo, K., Principles of Combustion, New York, NY, John Wiley and Sons, 1986.

4. Raithby, G. and Chui, E., "A Finite-Volume Method for Predicting Radiant Heat Transfer in Enclosures with Participating Media", Journal of Heat Transfer, Vol. 112, 1990, pp. 415423.

5. Rehm, R. and Baum, H., "The Equations of Motion for Thermally Driven, Buoyant Flows", Journal of Research of the NBS, Vol. 83, 1978, pp. 297-308.

6. Mahalingam, S. et al., "Analysis and Numerical Simulation of a Nonpremixed Flame in a Corner", Combustion and Flame, Vol. 118, 1999, pp. 221-232.

7. Siegel, R. and Howell, J.R. Thermal Radiation Heat Transfer, 3rd Edn., Philadelphia, PA, Hemisphere Publishing Corp., 1992.

8. Karlsson, B. and Quintiere, J., Enclosure Fire Dynamics, Boca Raton, FL, CRC Press, 2000.

9. Mulholland, G. and Choi, M. Measurement of the Mass Specific Extinction Coefficient for Acetylene and Ethene Smoke Using the Large Agglomerate Optics Facility, 27th Symposium on Combustion, The Combustion Institute, 1998, pp. 1515-1522.

10. Grosshandler, W., RADCAL: A Narrow-Band Mode for Radiation Calculations in a Combustion Environment, NIST Technical Note 1402, National Institute of Standards and Technology, Gaithersburg, MD, 1993.

11. Baum, H. et al., "Three Dimensional Simulations of Fire Plume Dynamics", In: Proceedings of the 5th International IAFSS Symposium, Fire Safety Science, 1997, pp. 511-522.

12. Blevins, L., "Behavior of Bare and Aspirated Thermocouples in Compartment Fires, HTD99-280", In: Proceedings of the ASME National Heat Transfer Conference, Albuquerque, NM, 1999. 
13. Schall, M. and Valencia, L., Data Compilation of the HDR Containment for Input Data Processing for Pre-Test Calculations, PHDR Working Report 3.143/79, Project HDR Nuclear Center, Karlsruhe, Germany, 1982.

14. Floyd, J., Evaluation of the Predictive Capabilities of Current Computational Methods for Fire Simulation in Enclosures Using the HDR T51 and T52 Tests with a Focus on Performance-Based Fire Codes, Ph.D. Dissertation, University of Maryland, College Park, MD, 2000.

15. Floyd, J., Comparison of CFAST and FDS for Fire Simulation with the HDR T51 and T52 Tests, NISTIR-6866, National Institute of Standards and Technology, Gaithersburg, MD, 2002. 